Leila Zeinalzadeh AHRANJANI, PhD

E-mail: lzeinalzade@yahoo.com (Corresponding author)

Department of Mathematics, Islamic Azad University

Salmas Branch, Salmas, Iran

Associate Professor Reza Farzipoor SAEN, PhD

E-mail: RFarzipoorsaen@su.edu.om

Department of Industrial Management, Islamic Azad University

Karaj Branch, Karaj, Iran

Iraj Molaei GHOLENJI, PhD

E-mail: i_molaei57@yahoo.com

Department of Accounting, Islamic Azad University

Salmas Branch, Salmas, Iran

\title{
ESTIMATING CAPACITY UTILIZATION IN NETWORK DEA IN THE PRESENCE OF UNDESIRABLE OUTPUTS
}

\begin{abstract}
This paper aims to evaluate the performance of two-stage production processes through the estimation of capacity utilization with presence of undesirable outputs. Capacity utilization is a determinant which measures the capability of decision making units to utilize fixed inputs in short-run. Hence, to develop it on these systems, factors production are categorized into fixed and variable inputs. Then the SBM-based two-stage DEA model is modified to apply the weak disposability to modeling undesirable factors. The study progressed to consider the effect of intermediate measures on capacity utilization. Ultimately the presented numerical example illustrates the effectiveness and applicability of current model.
\end{abstract}

Keywords: Two-stage DEA, Capacity Utilization, Undesirable output, Weak disposability, Intermediate measure.

\section{Introduction}

Since production generally requires the accessibility to production factors, its increase could be achieved through two ways: improvement in production factors and their optimal utilization. These days, taking resource limitations into account, production improvement and optimal utilization of production factors are substantially possible through employing optimal resource managements and methods. It could be stated one of the ways to optimize synthetic production factors is to boost efficiency through optimal utilization of capacity.

Managers and policymakers in diverse manufacturing and service firms are always obsessed with performance rate as well as potential production. Thereupon, 
technical and valid reactions to these issues extensively affect their standpoint and plan. Capacity utilization, one of prominent economic indicators, displays the degree of exploitation in companies. Accordingly, this concept mainly refers to relation between actual output (actual production) produced by embedded equipment as well as accessible output (potential production) produced providing taking all available equipment into use (Ihejirika and Warri, 2012). The same way, Ray (2011) explicating capacity utilization, applies the term unwanted or unintentional additional production capacity for the differentiation between production capacity and actual production. Put simply, capacity plays a significant role in economic analysis. Indeed, there are myriad definitions and misunderstandings on so-called capacity.

Altogether, there are two diverse economic and engineering standpoints regarding production capacity, in the way that technically feasible issue probably isn't economically desirable. Regardless of its varied definitions, capacity directly stands for potential production level. Likewise, Ray (2011) considers the gap occurred between technical and economic capacity utilization as programmed and intentional extra empty capacity.

It should be claimed that from technical standpoint, potential output is obtainable technically. Thereupon maximum physical product is thoroughly achievable when fixed inputs are supportable and variable inputs totally used up. Furthermore, physical concept of capacity implies maximum potential output in a production unit with given technology and capital accumulation without any limitation on short term unstable production factors. Gold (1955) is a pioneer researcher to put forth an argument over capacity measurement. He firmly states Production capacity estimation appears in two ways: the estimation of total possible production rate and synthetic production capacity. Simply put, Johansen (1968) introduced capacity utilization's theoretical framework. He defined the technical measure of capacity output as, " the maximum amount that can be produced per unit of time exiting plant and equipment, provided the availability of variable factors of production is not restricted" (1968, p. 68). In recent year, some studies have based on Johansen's definition and employed the Data Envelopment Analysis (DEA) methodology to measure capacity output and CU's manufacturing and service sectors (Arfa et al (2017), Yang et al (2018), Yu et al (2016), Yang and Fukuyama (2018) and Zhang et al (2016)). DEA is the most appropriate nonparametric evaluation technique to measure relative efficiency of decision making units (DMUs) which convert multi-inputs into multi-outputs. This technique was first introduced by Charnes et al. (1978) and then extended by other researchers.

Fare (1984) employed the DEA method to estimate production capacity firms. The offered methodology was the weaker version of the Johansen's definition in which the outputs are limited by fixed production factors. Furthermore, he represented that the plant capacity concept cannot be obtained for certain parametric technology (e.g., Cobb-Douglas). In fact, the necessary and sufficient conditions are provided for existence of plant capacity. Fare's approach was modified and developed by Fare et.al $(1989,1994)$. Fare et.al (1994) illustrated 
Estimating Capacity Utilization in Network DEA in the Presence of Undesirable Outputs

that proposed CU measure by Fare et.al (1989) may be biased downward. They suggested an output oriented measure of technical efficiency that could be applied to compute the capacity output. Later, their technique has been widely utilized in varied sectors (Arfa et al (2017), Yu et al (2016), Yang and Fukuyama (2018)). To introduce a non-radial measure of CU, Cooper et al. (2007) developed slack-based measure (SBM) model to calculate these concepts. Their approach is used to study CU in banking industry (Sahoo and Tone (2009)). Moreover, Arfa et al (2017) investigated the technical measure of CU for a sample of Public District Hospitals (PDH) in Tunisia. They applied dual DEA approach to measure individual PDHs capacity utilization. Yu et al (2016) used a slack-based DEA model to estimate the physical CU. They also calculated cost gap between actual and global long-run minimum costs. What's more the method is applied on a real case study of 13 lowcost carriers around the world for the year 2010. A dynamic CU measure, applying a dynamic SBM-DEA model, was first defined by Zhang et al (2016). Meanwhile they computed the CU of China's industrial sector.

Unlike researches under took in the CU field, Cesaroni et al. (2017) employed DEA technique to propose a new input-oriented measure of plant capacity utilization. They illustrated the convexity effect of technology on both the output- and input-oriented plant capacity concepts.

Recently, Yang and Fukuyama (2018-omega) developed a generalized capacity utilization indicator in presence of bad outputs to determine the regional production potential of Chinese provinces. The current indicator measures the extent to which the current variable inputs of the evaluated DMUs are consumed.

In fact, these inputs produce the maximal amounts of good outputs. In this manner the indicator requires no information on prices. They defined it as the difference between two directional distance functions. Another study conducted by Yang et al. (2018) to investigate CU's Chinese manufacturing industries. Their CU definition indicator of CU is established on both DEA methodology and directional distance functions. The aforementioned studies applied the traditional DEA models to estimate each production unit's capacity utilization. In traditional DEA models, the DMUs are treated as black-boxes that convert inputs to outputs. Ignoring internal structure of DMUs, they are unable to deliver sufficient management information to managers and decision makers. This defect is specifically perceptible in facing some production processes such as two-stage production systems. So, they cannot be directly utilized to evaluate the performance of twostage network production processes. See Kao (2014) for more details.

Unlike referred studies, Ahranjani and Matin (2018) considered the current concept on two-stage production processes. They introduced and modified the radial two-stage DEA model to extend the Fare et al (1994)'s work. They also demonstrated the efficacy of intermediate production on $\mathrm{CU}$ achieved values. Furthermore, their study describes evaluated DMUs as basic two-stage processes where all intermediate measures produced by first stage are consumed by second 
for production. The present study aims to investigate this indicator on twostage network production systems in the presence of undesirable factors. Then the influence of undesirable intermediate production as well as undesirable final outputs on systems is put under carful study. Hence, to develop this indicator on the general two-stage production processes, the SBM network DEA model is modified to use the weak disposability to modeling undesirable factors.

The rest of paper is organized as follows. The required background is presented in section 2. The two-stage structures are introduced in section 3. Estimation of CU scores in two-stage production systems with undesirable factors is provided in section 4. A numerical example illustrates the effectiveness of the proposed model in section 5. Conclusions are drawn and further research outlined in a final section.

\section{Background}

There are two fundamental approaches in DEA, radial and non-radial, which can measure the efficiency of DMUs. Each model has specific characteristics. For example, the radial models consider proportional changes of input or output resources and mostly neglect the existence of slacks in reporting the efficiency scores, whereas the non-radial models directly work with input excesses and output shortfalls. Hence, they are able to detect efficient units from inefficient ones. In these models the alterations of inputs and outputs are not proportional therefore the reduction (increase) at different rates are allowed in them. One of the most important non-radial models in DEA was introduced by Tone (2001) that called Slack-Based Measure (SBM). Necessary to add that, in recent years, the estimation of production systems efficiency has been usually done by the SBM.

2.1 The Slack-Based Measure model with undesirable outputs

Slack-based measure is widely utilized as a non-radial DEA model which in three variations, i.e. input-, output-, and non-oriented, introduced by Tone (2001).

Non-oriented SBM is defined by Tone (2001) as follows:

$$
\begin{array}{cc}
\min \rho_{o}=\frac{1-\frac{1}{m} \sum_{i=1}^{m} \frac{s_{i}^{-}}{x_{i o}}}{1+\frac{1}{s} \sum_{r=1}^{s} \frac{s_{r}^{+}}{y_{r o}}} & \\
\text { s.t } \quad \sum_{j=1}^{n} \lambda_{j} x_{i j}+s_{i}^{-}=x_{i j} & i=1, \ldots, k \\
\sum_{r=1}^{s} \lambda_{j} y_{r j}-s_{r}^{+}=y_{r o} & r=1, \ldots, s \\
\lambda_{j} \geq 0 & j=1, \ldots, n
\end{array}
$$

This model put asides the assumption of proportionate changes in inputs and outputs and directly applies input and output slacks in efficiency measure. It also satisfies some interesting properties, namely, it is unit invariant and monotone 
Estimating Capacity Utilization in Network DEA in the Presence of Undesirable Outputs

decreasing in each input/output slack. Suppose there are n homogeneous DMUs each of which has three types of variables, i.e. inputs, desirable outputs and undesirable outputs which are indicated as vectors $x \in R^{m}, y^{g} \in R^{S_{1}}$ and $y^{b} \in R^{S_{2}}$ respectively. Note that $\mathrm{m}, S_{1}$ and $S_{2}$ denote the number of the variables. Also, assume that all data are positive $\left(x, y^{g}\right.$ and $\left.y^{b}>0\right)$.

The production possibility set is illustrated as follows:

$$
P=\left\{\left(x, y^{g}, y^{b}\right) \mid x \text { can produce }\left(y^{g}, y^{b}\right)\right\}
$$

Tone (2004) developed the Tone's SBM model to introduce a new model with undesirable outputs as follows:

$$
\begin{aligned}
\varphi^{*}=\min & \frac{\left(1-\frac{1}{m} \sum_{i=1}^{m} \frac{s_{i}^{-}}{x_{i o}}\right)}{\left(1+\frac{1}{S_{1}+S_{2}}\left(\sum_{r=1}^{S_{1}} \frac{s_{r}^{+}}{y_{r o}^{g}}+\sum_{r=1}^{S_{2}} \frac{s_{r}^{u}}{y_{r o}^{b}}\right)\right)} \\
\text { s.t } \quad & \sum_{j=1}^{n} \lambda_{j} x_{i j}+s_{i}^{-}=x_{i o} \quad i=1, \ldots, m \\
& \sum_{r=1}^{s} \lambda_{j} y_{r j}^{g}-s_{r}^{+}=y_{r o}^{g} \quad r=1, \ldots, S_{1} \\
& \sum_{r=1}^{s} \lambda_{j} y_{r j}^{b}+s_{r}^{b}=y_{r o}^{b} \quad r=1, \ldots, S_{2} \\
& \lambda_{j}, s_{i}^{-}, s_{r}^{+}, s_{r}^{u} \geq 0 \quad j=1, \ldots, n ; r=1, \ldots, S_{1,2} ; i=1, \ldots, m
\end{aligned}
$$

Where $\lambda_{j}$ is the intensity variable, and $s^{-}$and $s^{+}\left(s^{b}\right)$ denote the inputs and the desirable (undesirable) outputs slack vectors respectively. Note also that model (1) is a fractional program, which can transform into an equivalent linear form (Charnes-Cooper transformation 1962).

2.1.1 output-oriented SBM model with undesirable outputs

Tone (2004) presented output-oriented of the model (2) as follows:

$$
\begin{aligned}
\varphi^{*}=\operatorname{Max} & \left(1+\frac{1}{S_{1}+S_{2}}\left(\sum_{r=1}^{s_{2}} \frac{s_{r}^{+}}{y_{r o}^{g}}+\sum_{r=1}^{s_{2}} \frac{s_{r}^{u}}{y_{r o}^{b}}\right)\right) \\
\text { s.t } \quad & \sum_{j=1}^{n} \lambda_{j} x_{i j} \leq x_{i o} \quad i=1, \ldots, m \\
& \sum_{r=1}^{s} \lambda_{j} y_{r j}^{g}-s_{r}^{+}=y_{r o}^{g} \quad r=1, \ldots, S_{1}
\end{aligned}
$$


Leila Zeinalzadeh Ahranjani, Reza Farzipoor Saen, Iraj Molaei Gholenji

$$
\begin{array}{ll}
\sum_{r=1}^{s} \lambda_{j} y_{r j}^{b}+s_{r}^{u}=y_{r o}^{b} & r=1, \ldots, S_{2} \\
\lambda_{j}, s_{i}^{-}, s_{r}^{+}, s_{r}^{u} \geq 0 & j=1, \ldots, n ; r=1, \ldots, S_{1,2} ; i=1, \ldots, m
\end{array}
$$

These models are applicable for manufacturing firms as black boxes where some inputs are consumed to produce some outputs. Therefore, they are not useful to evaluate the performance of network systems due to overestimating the overall efficiency scores.

\section{Two-stage production processes}

The simplest structure of a network system is two-stage production process which maintains the series relationship between two processes. Kao (2014) puts forward two types of two-stage network structure: basic and general (see Figure 1). In the former structure, all outputs of the stage 1 are used as only inputs in the stage 2. The latter which is illustrated in Fig. $b$ is the extension of the basic two-stage structure. In the current structure, to produce final outputs both stages are allowed to consume external inputs.

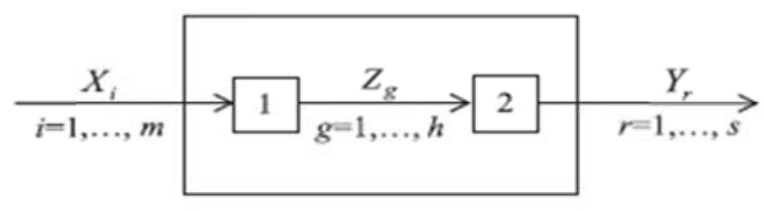

Figure a: basic two-stage structure

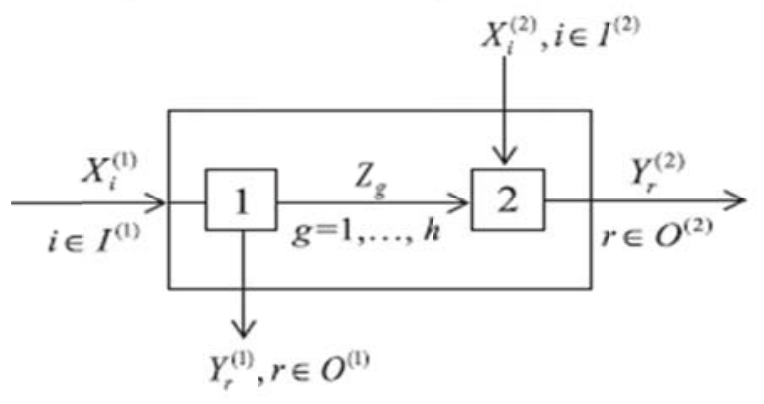

Figure b: general two-stage structure

Figure 1: Two-stage network structures.

The large number of DEA models is introduced to evaluate the performance of two-stage production processes. These models developed the basic DEA methodology by taking two sub-processes for each system. It provides a state of "look inside" the DMUs to identify the sources of inefficiencies. 
Estimating Capacity Utilization in Network DEA in the Presence of Undesirable Outputs

Figure 1 illustrates two types of two-stage network structures. Fig a are mostly worked and practiced in many researches, which states whole outputs of first stage are the only inputs in second stage (Kao (2014)).

\subsection{Capacity utilization in DEA framework}

The physical measure of capacity utilization is an important economic parameter of performance which points out the ability of firms to use their fixed factors in the short-run. On this basis, the inputs have got two categories for each DMU: fixed $\left(x^{f}\right)$ \& variable $\left(x^{v}\right)$ i.e. $x=\left(x^{f}, x^{v}\right)$. Note that all factors of production can be altered in the long-run.

To calculate CU measure, Cooper et al. (2006) applied the output oriented SBM model to present non-radial measure of capacity output and considered DMUs access to many variable inputs needed for full capacity. Therefore, by the omission of corresponding restrictions of variable inputs following CRS model is formed as:

$$
\begin{array}{ll}
\max & \rho_{o}^{F}=\left(1+\frac{1}{s} \sum_{r=1}^{s} \frac{s_{r}^{+}}{y_{r o}}\right) \\
\text { s.t } \quad \sum_{\substack{j=1 \\
s}}^{n} \lambda_{j} x_{i j}^{F} \leq x_{i o}^{F} \quad & i=1, \ldots, k \\
\sum_{r=1}^{s} \lambda_{j} y_{r j}-s_{r}^{+}=y_{r o} & r=1, \ldots, s \\
\lambda_{j} \geq 0 & j=1, \ldots, n
\end{array}
$$

Suppose that $\rho_{o}^{*}$ and $\rho_{o}^{* F}$ are the optimal values obtained by solving models (1) and (4) respectively. According to CU definition, its measure is calculated by following equation (Cooper et al. 2006):

$$
C U=\frac{\rho_{o}^{*}}{\rho_{o}^{* F}}(\leq 1)
$$

Recent relation indicates that the produced gap between actual and capacity output which is specifically created by inefficient utilization of fixed inputs is measured by CU. The mentioned relation under the CRS assumption and applying the redial model is proposed by Fare et al. (1994). The created model is named the plant capacity utilization measure of the DMU. In Fare et al. (1994) argument, CU measure is the most technically efficient output level ration to the capacity output level. 
4. Estimation of physical capacity utilization with undesirable factors In this section, it is assumed that all DMUs have got two-stage structure as figure 2. To assess each DMU's capacity output, the following CRS two-stage DEA model is proposed:

$$
\begin{aligned}
& \max \eta_{\mathrm{F}}=1+\frac{1}{\mathrm{~s}_{1}+\mathrm{P}}\left(\sum_{\mathrm{r}=1}^{\mathrm{s}_{1}} \frac{\mathrm{s}_{\mathrm{r}}^{+}}{\mathrm{y}_{\mathrm{ro}}}+\sum_{\mathrm{p}=1}^{\mathrm{P}} \frac{\mathrm{s}_{\mathrm{p}}^{+}}{\mathrm{v}_{\mathrm{po}}}\right) \\
& \text { s.t. } \quad \sum_{j=1}^{n} \lambda_{j} x_{i j}^{f} \leq x_{i o}^{f} \quad i=1, \ldots, M_{1} \\
& \sum_{j=1}^{n} \lambda_{j} v_{p j}-s_{p}^{+}=v_{p o} \quad p=1, \ldots, P \\
& \sum_{j=1}^{n} \lambda_{j} w_{q j}=w_{q o} \quad q=1, \ldots, Q \\
& \sum_{j=1}^{n} \mu_{j} v_{p j}^{f} \leq v_{p o}^{f} \quad p=1, \ldots, P_{1} \\
& \sum_{\mathrm{j}=1}^{\mathrm{n}} \mu_{\mathrm{j}} \mathrm{z}_{\mathrm{kj}}^{\mathrm{f}} \leq \mathrm{z}_{\mathrm{ko}}^{\mathrm{f}} \quad \mathrm{k}=1, \ldots, \mathrm{K}_{1} \\
& \sum_{j=1}^{n} \mu_{j} y_{r j}^{g}-s_{r}^{+}=y_{r o}^{g} \quad r=1, \ldots, s_{1} \\
& \sum_{j=1}^{n} \mu_{j} y_{r j}^{b}=y_{\text {ro }}^{b} \quad r=1, \ldots, S_{2} \\
& \lambda_{\mathrm{j}}, \mu_{\mathrm{j}} \geq 0 \quad \mathrm{j}=1, \ldots, \mathrm{n} \\
& \mathrm{s}_{\mathrm{p}}^{+}, \mathrm{s}_{\mathrm{r}}^{+} \geq 0 \quad \mathrm{p}=1, \ldots, \mathrm{P} ; \mathrm{r}=1, \ldots, \mathrm{S}_{1}
\end{aligned}
$$

In the above model, the presumption is that DMU under evaluation has availability to numerous variable inputs required for full capacity. Accordingly the corresponding restrictions from the model are removed. Note that the treatment of variable inputs is regarded as the only major difference between two models (3) and (5).

Let $\eta^{*}$ and $\eta_{F}^{*}$ be the optimal value of models (3) and (5) respectively, by definition, the physical measure of capacity utilization in two-stage production systems can be computed as relation follow:

$$
C U\left(D M U_{O}\right)=\frac{\eta^{*}}{\eta_{F}^{*}}
$$

It is obvious that $\eta_{F}^{*} \geq \eta^{*}$. Therefore, the value of this indicator can be no greater than one. Considering recent relation, we can classify DMUs into two categories: 
Estimating Capacity Utilization in Network DEA in the Presence of Undesirable Outputs

- $\quad C U=1$ i.e. DMU cannot produce more output using the current fixed inputs. In other words, it has ability to utilize their fixed factors in the short-run.

- $C U<1$ i.e. these firms have excess capacity and could produce more than their current levels.

It should be noted that the current measure is not downward biased and lacks of any technical inefficiency. Furthermore, $((1-C U) * 100)$ is regarded as the percentage which its capacity does isn't used by DMU.

\section{Numerical example}

In this section, a numerical example is considered to represent the results and the effectiveness of proposed model. The current data is extracted from Amirteimoori et al. (2014)'s paper where the performance evaluation of 13 poultry farms is discussed. As it was illustrated on figure (A), there is structural consistency between demonstrated two-stage construction with the performance of poultry farms as an industrial active unit. Amirteimoori et al. (2014) illustrated and modeled each poultry farm (DMU) as a two-stage production process which stage 1 comprises first 21 days and stage 2 comprises an interval from 22th day to the end.

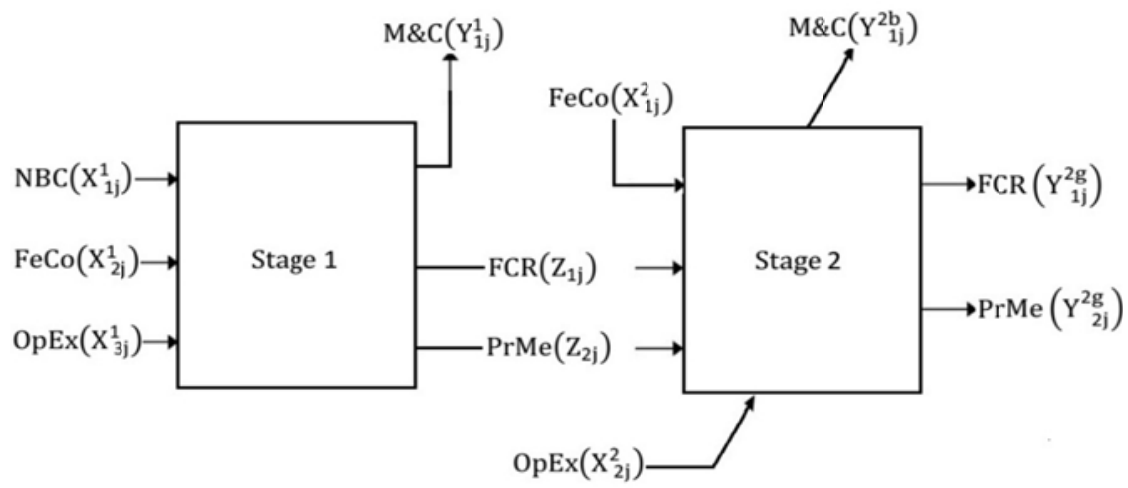

Figure A. Two-stage network of poultry farm

The data set involves 13 DMUs, three inputs (New Born Chicks- $x_{1}$, Feed Cost- $x_{2}$ and Operational Expenses- $x_{3}$ ), two desirable intermediate measures (Feed Conversion Ratio- $v_{1}$ and Produced Meat $-v_{2}$ ), one undesirable output from stage 1 that leaves the system (Mortality and Condemn-w), two extra inputs to stage 2 (Feed Cost- $z_{1}$ and Operational Expenses- $z_{2}$ ) and three final outputs from stage 2 (Feed Conversion Raito- $y_{1}$, Produced Meat- $y_{2}$ and Mortality and Condemn- $y_{3}$ ). Also, note that $y_{1}$ and $y_{2}$ are two good (desirable) outputs and $y_{3}$ is one bad 
Leila Zeinalzadeh Ahranjani, Reza Farzipoor Saen, Iraj Molaei Gholenji

(undesirable) output by second stage. Furthermore, it should be mentioned that $x_{1}$ stands for the only variable input while $x_{2}$ and $x_{3}$ are representative fixed elements. Table 1 and 2 report them.

Table 1. Data of 13 poultry farms (information of stage 1)

\begin{tabular}{|c|c|c|c|c|c|c|}
\hline \multirow[b]{3}{*}{ DMU } & \multicolumn{6}{|c|}{ Stage 1} \\
\hline & \multicolumn{3}{|c|}{ Input } & \multirow{2}{*}{$\begin{array}{c}\text { Output } \\
\text { M\&C } \\
(w)\end{array}$} & \multicolumn{2}{|c|}{ intermediate } \\
\hline & $\begin{array}{c}\text { NBC } \\
\left(x_{1}\right)\end{array}$ & $\begin{array}{c}\text { FeCo } \\
\left(x_{2}\right)\end{array}$ & $\begin{array}{c}\text { OpEx } \\
\left(x_{3}\right)\end{array}$ & & $\begin{array}{c}\text { FCR } \\
\left(v_{1}\right)\end{array}$ & $\begin{array}{c}\text { PrMe } \\
\left(v_{2}\right)\end{array}$ \\
\hline 1 & 12700 & 148500 & 57370 & 467 & 1.69 & 6691.5 \\
\hline 2 & 14670 & 171740 & 63900 & 513 & 1.65 & 7871.3 \\
\hline 3 & 13300 & 154930 & 63220 & 1263 & 1.72 & 6921.3 \\
\hline 4 & 15000 & 182880 & 66590 & 421 & 1.71 & 8280.9 \\
\hline 5 & 12000 & 147490 & 57030 & 758 & 1.68 & 6340.5 \\
\hline 6 & 14000 & 165080 & 63640 & 1098 & 1.70 & 7134.8 \\
\hline 7 & 13000 & 168930 & 62020 & 646 & 1.75 & 7202.4 \\
\hline 8 & 14900 & 175430 & 71680 & 821 & 1.62 & 7475.9 \\
\hline 9 & 13500 & 169520 & 62300 & 518 & 1.71 & 7399.7 \\
\hline 10 & 12800 & 144130 & 60930 & 623 & 1.63 & 6356.4 \\
\hline 11 & 19800 & 235970 & 80960 & 1042 & 1.67 & 10373.2 \\
\hline 12 & 11000 & 133540 & 51340 & 385 & 1.68 & 5933.8 \\
\hline 13 & 12600 & 148870 & 57210 & 479 & 1.63 & 6521.1 \\
\hline
\end{tabular}

Table 2. Data of 13 poultry farms (information of stage 2)

\begin{tabular}{|c|c|c|c|c|c|}
\hline \multirow{3}{*}{ DMU } & \multicolumn{5}{|c|}{ Stage 2 } \\
\cline { 2 - 6 } & \multicolumn{2}{|c|}{ Input } & \multicolumn{3}{|c|}{ Output } \\
\cline { 2 - 6 } & $\begin{array}{c}\text { M\&C } \\
\left(\boldsymbol{y}^{\boldsymbol{b}}\right)\end{array}$ & $\begin{array}{c}\text { PrMe } \\
\left(\boldsymbol{y}_{\mathbf{2}}^{\mathbf{}}\right)\end{array}$ & $\begin{array}{c}\text { FCR } \\
\boldsymbol{(}_{\mathbf{1}}^{\boldsymbol{g}} \mathbf{)}\end{array}$ & $\begin{array}{c}\text { OpEx } \\
\left(\mathbf{z}_{\mathbf{2}}\right)\end{array}$ & $\begin{array}{c}\text { FeCo } \\
\left(\mathbf{z}_{\mathbf{1}}\right)\end{array}$ \\
\hline 1 & 173 & 28582.2 & 1.98 & 97920 & 438500 \\
\hline 2 & 197 & 32387.2 & 1.93 & 110160 & 491760 \\
\hline 3 & 306 & 28506.3 & 2.00 & 106150 & 435410 \\
\hline 4 & 79 & 34075.0 & 1.95 & 126650 & 518560 \\
\hline 5 & 256 & 26256.5 & 1.98 & 100700 & 415130 \\
\hline 6 & 263 & 29828.0 & 1.97 & 113700 & 449710 \\
\hline 7 & 144 & 30158.7 & 2.03 & 110550 & 468450 \\
\hline 8 & 214 & 33414.6 & 2.04 & 119100 & 532190 \\
\hline 9 & 246 & 30439.0 & 1.94 & 106770 & 480800 \\
\hline 10 & 167 & 28223.5 & 2.03 & 105240 & 433090 \\
\hline 11 & 336 & 44581.2 & 2.01 & 144430 & 685800 \\
\hline 12 & 89 & 25683.4 & 2.00 & 86880 & 378100 \\
\hline 13 & 186 & 28405.3 & 1.88 & 102420 & 440730 \\
\hline
\end{tabular}


Estimating Capacity Utilization in Network DEA in the Presence of Undesirable Outputs

Based on the method introduced in the previous section, the CU scores could be determined in following three steps:

i. Calculation of the maximum output through all observed inputs.

ii. Determination of each DMU's capacity through observed fixed inputs, giving unlimitation to variable inputs (accordant with Johansen's definition of capacity).

iii. Estimation a technical measure of capacity utilization applying the ration of the first two steps.

To fulfill this purpose, the models (3) and (5) are applied to calculate the maximum output with all production factors (fixed and variable inputs) and capacity output of each DMU with only fixed production factors respectively. Also, we will use the formula (6) to determine each DMU's CU. These models are coded using LINGO 11 software. Table 3 shows the obtained CU measures for each of these DMUs in two different cases (Two-stage and Black box positions).

It is significant to add that in the black box position, the intermediate factors are ignored. In this position, the DMU is treated and evaluated as single stage system which transforms the initial inputs to the final outputs.

Table 3. CU estimation of 13 poultry farms in two different cases: Two-stage and Black box.

\begin{tabular}{|c|c|c|c|c|c|c|}
\hline DMU & $\begin{array}{c}\boldsymbol{\rho}^{*} \\
\text { Two- } \\
\text { Stage }\end{array}$ & $\begin{array}{c}\boldsymbol{\rho}^{*} \\
\text { Black } \\
\text { box }\end{array}$ & $\begin{array}{c}\boldsymbol{\rho}_{\boldsymbol{F}}^{*} \\
\text { Two- } \\
\text { Stage }\end{array}$ & $\begin{array}{c}\boldsymbol{\rho}_{\boldsymbol{F}}^{*} \\
\text { Black } \\
\text { box }\end{array}$ & $\begin{array}{c}\boldsymbol{C} \boldsymbol{U}_{\text {Two-Stage }} \\
=\left(\boldsymbol{\rho}^{*} / \boldsymbol{\rho}_{\boldsymbol{F}}^{*}\right)\end{array}$ & $\begin{array}{c}\boldsymbol{C} \boldsymbol{U}_{\text {Black box }} \\
=\left(\boldsymbol{\rho}^{*} / \boldsymbol{\rho}_{\boldsymbol{F}}^{*}\right)\end{array}$ \\
\hline 1 & 1.04983 & 1.05235 & 1.04983 & 1.05235 & 1.00000 & 1.00000 \\
\hline 2 & 1.05872 & 1.11766 & 1.05872 & 1.11766 & 1.00000 & 1.00000 \\
\hline 3 & 1.00000 & 1.00000 & 1.00000 & 1.00000 & 1.00000 & 1.00000 \\
\hline 4 & 1.00000 & 1.00000 & 1.00000 & 1.00000 & 1.00000 & 1.00000 \\
\hline 5 & 1.00820 & 1.00000 & 1.01901 & 1.04539 & 0.98939 & 0.95658 \\
\hline 6 & 1.01619 & 1.07863 & 1.01619 & 1.07863 & 1.00000 & 1.00000 \\
\hline 7 & 1.04157 & 1.00000 & 1.07612 & 1.11453 & 0.96789 & 0.89724 \\
\hline 8 & 1.17617 & 1.12908 & 1.17617 & 1.14739 & 1.00000 & 0.98404 \\
\hline 9 & 1.09130 & 1.11582 & 1.11229 & 1.11582 & 0.98113 & 1.00000 \\
\hline 10 & 1.04285 & 1.04516 & 1.04285 & 1.04516 & 1.00000 & 1.00000 \\
\hline 11 & 1.00000 & 1.00000 & 1.00000 & 1.00000 & 1.00000 & 1.00000 \\
\hline 13 & 1.00000 & 1.00000 & 1.00000 & 1.00000 & 1.00000 & 1.00000 \\
\hline
\end{tabular}

The comparison of obtained CU values from the two different cases (Two-stage and Black box) leads to the following results. According to table 3, taking or ignoring the intermediate factors affects in estimating CU scores for special DMU. It is significant to add that they are not necessarily the same in the both positions. 
As an example, consider $D M U_{8}, D M U_{9}$ and $D M U_{13}$. The assessment of $D M U_{8}$ and $D M U_{13}$ in two-stage position $C U=1$ i.e. these firms are unable to produce more output consuming the current fixed inputs. However, when they are analyzed in black box form, their corresponding CU are less than 1 and have excess capacity in black box position. Accordingly, analyzing $D M U_{9}$ as a two-stage system indicates that this firm possesses needed potential to produce more output with the current fixed inputs because of $C U<1$, notwithstanding it fully utilizes its fixed inputs when it is analyzed as a black box. These results indicate that intermediate products play an important role in the evaluative performance.

The results of table 3 in two-stage position show that all poultry firms except for $D M U_{5}, D M U_{7}$ and $D M U_{9}$ fully utilize their fixed inputs. In other words only $23 \%$ of total units don't operate with full capacity therefore they could increase their outputs without alternation in level of fixed inputs. Note that the obtained information of CU could help managers decide the performing improvement of DMUs. Since, fixed inputs are unaltered in the short-run so the managers should have great consideration on variable production factors.

In order to check the results of table 3, we consider the $D M U_{7}$ and use models (3) and (5) to evaluate and estimate the CU score of this firm. The following optimal values are obtained

$$
\rho^{*}=1.041568 \quad \text { and } \quad \rho_{F}^{*}=1.076123
$$

Now, we can calculate its corresponding CU by using relation (6) as follows:

$$
\begin{aligned}
C U_{D M U_{7}}=\frac{\rho^{*}}{\rho_{F}^{*}} & =\frac{1.041568}{1.076123}=0.967889 \cong 0.97 \text { or }\left(\left(1-C U_{D M U_{7}}\right) * 100\right) \\
& =0.03 \%
\end{aligned}
$$

Since $\mathrm{CU}_{\mathrm{DMU}_{7}}<1$ so this firm is able to produce more output consuming current fixed inputs. In other hand, $D M U_{7}$ only utilizes $97 \%$ of its capacity, indicating that $D M U_{7}$ should reduce its fixed inputs. This obtained measure illustrates that there is a possibility to improve its production by $3 \%$ without additional fixed inputs. Similar analyses can be carried out for other DMUs.

\section{Conclusion}

The conventional DEA models regard the production systems as black boxes which only their initial inputs and final outputs are effective to evaluate their efficiency. These models are not efficient enough in the evaluating performance of systems especially two-stage network production systems. The crucial reason of the inefficiency is the negligence of production units' internal structure and the inadvertence of the internal products. Hence, their obtained estimates often appear inaccurate. The present paper has investigated performance of the general twostage production systems through estimation of capacity utilization in the presence of undesirable factors. The capacity utilization is an important economic parameter (indicator) of performance which points out the ability of DMUs to use fixed factors of production in short-run. Therefore, in short-run these factors are classified into fixed and variable inputs. 
Estimating Capacity Utilization in Network DEA in the Presence of Undesirable Outputs

In order to provide a non-radial measure of this indicator to improve Cooper et al.'s work on these systems, the SBM-based network DEA model is offered. In fact, this model has applied the weak disposability to modeling network DEA with undesirable factors. An empirical example is presented in two different positions (Black-box and Two-stage) to illustrate the effect of intermediate products on CU value. The obtained values for some of units were not necessarily the same in the both positions. Likewise, the achieved results of two approaches (traditional \& network) indicated that regarding internal products in comparing to traditional method, it works more precisely and is more reliable for planning. The suggestion provided for the prospective researcher is to extend the fuzzy and stochastic version of proposed model.

\section{REFERENCES}

[1] Amirteimoori, A, Toloie-Eshlaghi, A, Homayoonfar, M. (2014), Efficiency Measurement in Two-Stage Network Structures Considering Undesirable Outputs. Int. J. Industrial Mathematics, 6 (1), 65-71;

[2] Arfa, C. Leleu, H. Goaied, M. Mosseveld, C, (2017), Measuring the Capacity Utilization of Public District Hospitals in Tunisia: Using Dual Data Envelopment Analysis Approach. Int. J. Heath Policy and Management, 6(1) 918 ;

[3] Cesaroni G, Kerstens K, Van de Woestyne I (2017), A New Input-Oriented Plant Capacity Notion: Definition and Empirical Comparison. Pacific Economic Review 22(4):720-739;

[4] Charnes, A, Cooper, W.W. (1962), Programming with Linear Fractional Functional. Naval Research Logistics Quarterly, 9, 181-185;

[5] Charnes, A, Cooper, W.W, Rhodes, E. (1978), Measuring the Efficiency of Decision Making Units. European Journal of Operational Research 2, 429-444;

[6] Cooper, W.W, Seiford, L.M, Tone, K. (2006), Data Envelopment Analysis: A Comprehensive Text with Models, Applications, References and DEA Solver Software. Springer-Verlag New York, Inc.;

[7] Färe, R. (1984), The Existence of Plant Capacity; International Economic Review, 25(1), 209-213;

[8] Färe, R, Grosskopf, S, Kokkelenberg, E.C. (1989), Measuring Plant Capacity, Utilization and Technical Change: A Nonparametric Approach; International Economic Review, Vol. 30, No. 3, 655-666;

[9] Färe, R, Grosskopf, S. (1994), C.A.K. Lovell, Production Frontiers. Cambridge University Press, Cambridge, U.K.;

[10] Gold, B. (1955), Foundations of Productivity Analysis; Pittsburgh:

Pittsburgh University Press; 
[11] Ihejirika, P.O. Warri, B. (2012), Capacity Utilization, Industrial Production Index and Dividend Payout Policy in Nigeria: An Autoregressive Distributed Lag (ARDL) Model Approach To Cointegration. Research Journal of Finance and Accounting, 3(6), 2222-2847;

[12] Johansen, L. (1968), Production Functions and the Concept of Capacity. In: Recent Research on the Function of Production. Namur, France: Namur University Center for Study and Research;

[13] Kao, C. (2014), Network Data Envelopment Analysis: A review. European Journal of Operational Research 239, 1-16;

[14] Kuosmanen, T. (2005), Weak Disposability in Nonparametric Production Analysis with Undesirable Outputs. American Journal of Agricultural Economics 87(4), 1077-1082;

[15] Ray, S.P. (2011), Measuring Capacity Utilization and Evaluating the Impact of Liberalization on Capacity Utilization of Indian Drug and Pharmaceutical Industry. Journal of emerging knowledge on emerging markets, vol,3, 13;

[16] Sahoo, B.K, Tone, K. (2009), Decomposing Capacity Utilization in Data Envelopment Analysis: An Application to Banks in India. European Journal of Operational Research 195, 575-594;

[17] Tone, K. (2001), A Slacks-based Measure of Efficiency in Data

Envelopment Analysis; European Journal of Operational Research 130, 498-509;

[18] Tone, K. (2004), Dealing with Undesirable Outputs in DEA: A Slacks-

Based Measure (SBM) Approach. Presentation at NAPW III, Toronto;

[19] Tone, K. Tsutsui, M. (2009), Network DEA: A Slacks-based Measure

Approach. European Journal of Operational Research, 197, 243-252;

[20] Yang G-l, Fukuyama H (2018), Measuring the Chinese Regional

Production Potential using a Generalized Capacity Utilization Indicator. Omega, 76: 112-127;

[21] Yang G-I, Fukuyama H, Song Y-y (2018), Estimating Capacity Utilization of Chinese Manufacturing Industries; Socio-economic Planning Sciences;

[22] Yu, M-M. Chang, Y-C. Chen, L-H. (2016), Measurement of Airlines'

Capacity Utilization and Cost Gap: Evidence from Low-cost Carriers. Journal of air transport Management 53, 186-198;

[23] Zeinalzadeh Ahranjani, L. Kazemi Matin, R. (2018), Technical Measure of Capacity Utilization in Two-Stage Production Systems: A Data Envelopment Analysis; Economic Computation and Economic Cybernetics Studies and Research, 52 (2), 235-249; ASE Publishing;

[24] Zhang, S. Chang, T.P. Jiang, W. (2016), Dynamic Capacity Utilization in China's Industrial Sector. The Empirical Economics Letters, 15(6), 593-599. 